\title{
Design and Implementation of TOPSIS and AHP Coach ranking System
}

\author{
Chenxiang Zhang \\ Suzhou Industrial Park Institute of Services Outsourcing, Suzhou 215123, China
}

Keywords: evaluating best coach, three-level metrics, time line horizon, AHP with TOPSIS

\begin{abstract}
We build a elaborate model for finding the best all time coach or coaches in a more subjective and equitable way. We put emphasis on the establishment of three-level metrics,influence of time line horizon, selection of assessment method and application of all sports.Considering the universality of the model,we creatively propose a three-level metrics system.Primary metrics can be used to evaluate coaches in every sport,which helps us form our excellent coaches' database. Middle metrics are determined by the kind of sports. Meanwhile it can test whether our database is reasonable. Advanced metrics are related to special awards or honors. We study influence of time line horizon through the development of sports and the number of teams and calculate time-dependent weights. According to the calculations,we make adjustments to some metrics value.Based on our former work, we get the final coach rankings by combining AHP with TOPSIS.
\end{abstract}

\section{Introduction}

Everyone has a set of criteria of the best coach in mind. In order to find the"best all time college coach"in a fair and equitable way which can be accepted by most people, we will tackle with three subproblems. Which metrics can be used to evaluate a coach's achievements?How does the time line horizon influence assessment of a coach?

What method should we use to find the best coach or coaches, and how to find?We set five primary metrics to form our excellent coaches' database. Using AHP, we get every metrics' weights which can be applied in latter algorithm. Based on the former work, we utilize TOPSIS ranking coaches of top five.

\section{Assumptions}

In this paper, we discuss coaches whose information was recorded by NCAA. When a sport has been developed to a certain scale, NCAA may have the whole records about this sport. Before this, the coaches can be neglected. Some coaches may coach in many fields; we choose the longest coach experience he ever worked on as his records. Our goal is to select the greatest coaches in every field. He must be single-minded All-round talent has little effect on final result[1].

We presume our data and information about coaches downloaded from internet is reliable. We cannot exclude the possibilities that records of some coaches are lost, but we think the data is relatively comprehensive.

\section{Step one: Establishment of three-level metrics}

In the last century, sports developed rapidly in American. At the same time, each sport event emerged large number of excellent coaches. In consideration of the huge quantity of the coaches and the diversification of the honor the coaches won, it's unreasonable to choose the best coach just by using some plain metrics, such as win-lose percentage. But there are some basic requirements for the excellent coaches in spite of the difference of the sport event. Hence, we creatively propose a three-level Metrics. 


\section{Level One: Primary Metrics}

An excellent coach should meet the Primary Requests which are the minimum standards that an excellent coach should be equipped. To select the excellent coaches,we set five metrics and establish a database.

Coaching Time.Generally, an old coach usually better than a younger one in that the more games he guide the more experience he owns. In other words, a coach of 30 years is better than a coach of 10 years in most cases.

Victories. A great coach not only possesses rich experience but also win a certain number of games as his (her) record to support his reputation and skill.

Winning Percentage.This metrics can direct reflect a coach's teaching level. Beyond the influence of a team's economic strength and the attention the college pay, a great coach's win-loss percentage should be higher relatively. In turn, teams who get good result may get sponsored by schools or local government. This is may start virtuous circle.

Highest Honor.It's crucial for a great coach to get highest honor in his field. Gaining the highest honor can bring the coach more attentions and approvals.

Media Influence.Besides admirable skills, a super coach should have a lot of fans and supporters. There are many activities of vote to select the best coach on the internet. Of course, the results are not absolute[2].

\section{Level Two: Middle Metrics}

Due to the particularity of a certain sport event, some sport events have special metrics. Let's take basketball for examples.

SRS (Simple Rating System).SRS is denominated in points above/below average, where zero is average. Non- Division games are excluded from the ratings.

Highest Victories in One Season.In a coach's career, (s) he may experience lots of season games. This metric tell us about the best achievement (s) he ever made.

Fastest to Milestone wins.This metric is the win-lose percentage when a coach first reaches 50 victories. It's used for head coaches with at least half their seasons at Division I.

AP Final (Final AP Poll Ranking).AP Final is ranking in final AP poll (poll taken before the conclusion of the NCAA tournament).

\section{Level Three: Advanced Metrics. There are no special rules for the advanced metrics.}

These metrics are mainly some special title or award by the media. It will be helpful to rank in step 3.

Selection of Coaches. By using the primarily metrics, we can select some outstanding coaches form the NCAA coaches record and form our database. Here are the basic factors that a outstanding basketball coach should be equipped with:

At least win a championship during the coach's coaching career. Coaching time is no less than 10 years. The win-loss percentage is not less than $50 \%$. The victories should be higher than 1.5 times average victories of all the coaches. No bad review form media. At least 15 coaches in every sport event database (if not satisfied, the above conditions can be adjusted). The result of selection of basketball shows in Table 1. 
Table 1 Selection of the Basketball Coaches

\begin{tabular}{|c|c|c|c|c|c|c|c|c|c|c|c|c|}
\hline coach & From & To & Yrs & G & W & $\mathrm{L}$ & W-L\% & GREG & CTRN & NCAA & $\mathrm{FF}$ & $\mathrm{NC}$ \\
\hline Phog Allen & 1906 & 1956 & 48 & 978 & 719 & 259 & 0.735 & 24 & 0 & 4 & 3 & 1 \\
\hline $\begin{array}{c}\text { Jim } \\
\text { Boeheim }\end{array}$ & 1977 & 2014 & 28 & 1256 & 942 & 314 & 0.75 & 11 & 5 & 30 & 4 & 1 \\
\hline $\begin{array}{c}\text { Jim } \\
\text { Calhoun }\end{array}$ & 1973 & 2012 & 20 & 1259 & 877 & 382 & 0.697 & 16 & 12 & 23 & 4 & 3 \\
\hline $\begin{array}{l}\text { Denny } \\
\text { Crum }\end{array}$ & 1972 & 2001 & 30 & 970 & 675 & 295 & 10696 & 15 & 11 & 23 & 6 & 2 \\
\hline $\begin{array}{c}\text { John } \\
\text { Calipari }\end{array}$ & 1989 & 2014 & 22 & 756 & 585 & 171 & 0.774 & 14 & 11 & 14 & 4 & 1 \\
\hline Hank Iba & 1930 & 1970 & 40 & 1085 & 752 & 333 & 10.693 & 15 & 0 & 8 & 4 & 2 \\
\hline $\begin{array}{c}\text { Mike } \\
\text { Krzyzewski }\end{array}$ & 1976 & 2014 & 39 & 1277 & 975 & 302 & 0.764 & 12 & 13 & 29 & 22 & 4 \\
\hline Bob Knight & 1966 & 2008 & 42 & 1273 & 899 & 374 & 0.706 & 11 & 0 & 28 & 5 & 3 \\
\hline Lute Olson & 1974 & 2007 & 34 & 1061 & 776 & 285 & 0.731 & 13 & 4 & 28 & 5 & 1 \\
\hline $\begin{array}{l}\text { Adolph } \\
\text { Rupp }\end{array}$ & 1931 & 1972 & 41 & 1066 & 876 & 190 & 0.822 & 28 & 13 & 20 & 6 & 4 \\
\hline Dean Smith & 1962 & 1997 & 36 & 1133 & 879 & 254 & 0.776 & 17 & 13 & 27 & 11 & 2 \\
\hline Bill Self & 1994 & 2014 & 21 & 693 & 524 & 169 & 0.756 & 15 & 7 & 15 & 2 & 1 \\
\hline $\begin{array}{c}\text { Jerry } \\
\text { Tarkanian }\end{array}$ & 1970 & 2002 & 30 & 963 & 761 & 202 & 0.79 & 18 & 8 & 18 & 4 & 1 \\
\hline $\begin{array}{c}\text { Roy } \\
\text { Williams }\end{array}$ & 1989 & 2014 & 26 & 902 & 715 & 187 & 0.793 & 15 & 6 & 23 & 7 & 2 \\
\hline $\begin{array}{c}\text { John } \\
\text { Wooden }\end{array}$ & 1947 & 1975 & 29 & 826 & 664 & 162 & 0.804 & 16 & 0 & 16 & 12 & 10 \\
\hline Bob Knight & 1965 & 2008 & 42 & 1273 & 899 & 374 & 0.706 & 11 & 0 & 28 & 5 & 3 \\
\hline
\end{tabular}

\section{Step Two: Ranking of the Excellent Coaches}

The Technique for Order of Preference by Similarity to Ideal Solution (TOPSIS)[Hwang and Yoon 1981] is a multi-criteria decision analysis method and based on the concept that the chosen alternative should have the shortest geometric distance from the positive ideal solution and the longest geometric distance from the negative ideal solution[3].

The key of TOSIS is determining the weight of each index more accurately. In order to get more accurate weights, we use the Analytic Hierarchy Process (AHP)[Saaty 1982].

The weight of each index is obtained by AHP calculation as follows Table 2:

Table 2AHP-derived weights

\begin{tabular}{cccccccc}
\hline Factors & Yrs & W & W-L\% & CREG & CTRN & FF & NC \\
\hline Weights & 0.0049 & 0.0049 & 0.13 & 0.2 & 0.13 & 0.16 & 0.27 \\
\hline
\end{tabular}

Then, we test the consistency of the preferences for this instance of the AHP. For good consistency: we get the principal eigenvalue and and . Our decision methods are perfectly accepted by consistency. Now we can calculate the index weight according to the AHP which can be used in the TOPSIS. Here we can tell the result of the college basketball coach rankings. Result shows in Table 3: 
Table 3 Rankings of college basketball coaches

\begin{tabular}{ccccccccc}
\hline \multirow{2}{*}{ Names } & $\begin{array}{c}\text { John } \\
\text { Wooden }\end{array}$ & $\begin{array}{c}\text { Adolph } \\
\text { Rupp }\end{array}$ & Mike & $\begin{array}{c}\text { Dean } \\
\text { Smith }\end{array}$ & Jim & Denny & $\begin{array}{c}\text { Bob } \\
\text { Knight }\end{array}$ & Roy \\
\hline Rankings & 1 & 2 & 3 & 4 & 5 & 6 & 7 & 8 \\
Index & 0.75 & 0.44 & 0.43 & 0.33 & 0.3 & 0.24 & 0.22 & 0.21 \\
\hline \multirow{2}{*}{ Names } & John & \multirow{2}{*}{ Jerry } & Phog & Bill Self & Hank Iba & $\begin{array}{c}\text { Lute } \\
\text { Ollen }\end{array}$ & $\begin{array}{c}\text { Jim } \\
\text { Boeheim }\end{array}$ & \\
\hline Rankings & 9 & 10 & 11 & 12 & 13 & 14 & 15 \\
Index & 0.19 & 0.17 & 0.17 & 0.13 & 0.13 & 0.12 & 0.11 \\
\hline
\end{tabular}

\section{References}

[1] Hwang, C.L.; Yoon, K. 1981. Multiple Attribute Decision Making: Methods and Applications. New York: Springer-Verlag.

[2] Yoon, K; Hwang, C. 1995. Multiple Attribute Decision Making: An Introduction. California: SAGE publications.

[3] Greene, R.; Devillers, R.; Luther, J.E.; Eddy, B.G. 2011. "GIS-based multi-criteria analysis". Geography Compass 5/6: 412-432. 